\title{
The technique of S2-alar-iliac screw fixation: a literature review
}

\author{
Ai-Min Wu \\ Wenzhou Medical University \\ Dong Chen \\ Wenzhou Medical University \\ Chun-Hui Chen \\ Wenzhou Medical University \\ Yu-Zhe Li \\ Wenzhou Medical University \\ Li Tan Li Tang \\ Wenzhou Medical University \\ Follow this and additional works at: https://jdc.jefferson.edu/neurosurgeryfp \\ see rextof the foruralationamauthors and the Surgery Commons \\ Let us know how access to this document benefits you
}

\section{Recommended Citation}

Wu, Ai-Min; Chen, Dong; Chen, Chun-Hui; Li, Yu-Zhe; Li Tang, Li Tan; Phan, Kevin; Singh, Kern; Haws, Brittany E.; Vanni, Daniele; Mosley, Yusef I.; Prasad, Srinivas K.; Harrop, James; Lin, ZhongKe; Lin, Yan; Ni, Wen-Fei; and Wang, Xiang-Yang, "The technique of S2-alar-iliac screw fixation: a literature review" (2017). Department of Neurosurgery Faculty Papers. Paper 135.

https://jdc.jefferson.edu/neurosurgeryfp/135

This Article is brought to you for free and open access by the Jefferson Digital Commons. The Jefferson Digital Commons is a service of Thomas Jefferson University's Center for Teaching and Learning (CTL). The Commons is a showcase for Jefferson books and journals, peer-reviewed scholarly publications, unique historical collections from the University archives, and teaching tools. The Jefferson Digital Commons allows researchers and interested readers anywhere in the world to learn about and keep up to date with Jefferson scholarship. This article has been accepted for inclusion in Department of Neurosurgery Faculty Papers by an authorized administrator of the Jefferson Digital Commons. For more information, please contact: JeffersonDigitalCommons@jefferson.edu. 


\section{Authors}

Ai-Min Wu, Dong Chen, Chun-Hui Chen, Yu-Zhe Li, Li Tan Li Tang, Kevin Phan, Kern Singh, Brittany E. Haws, Daniele Vanni, Yusef I. Mosley, Srinivas K. Prasad, James Harrop, Zhong-Ke Lin, Yan Lin, Wen-Fei Ni, and Xiang-Yang Wang 


\title{
The technique of S2-alar-iliac screw fixation: a literature review
}

\author{
Ai-Min Wu ${ }^{1}$, Dong Chen ${ }^{1}$, Chun-Hui Chen ${ }^{1}$, Yu-Zhe Li ${ }^{1}$, Li Tang $^{1}$, Kevin Phan ${ }^{2}$, Kern Singh $^{3}$, Brittany E. \\ Haws $^{3}$, Daniele Vanni ${ }^{4}$, Yusef I. Mosley ${ }^{5}$, Srinivas K. Prasad ${ }^{5}$, James S. Harrop ${ }^{5}$, Zhong-Ke Lin ${ }^{1}$, Yan Lin ${ }^{1}$, \\ Wen-Fei $\mathrm{Ni}^{1}$, Xiang-Yang Wang ${ }^{1}$; on behalf of AME Spine Surgery Collaborative Group
}

${ }^{1}$ Department of Spine Surgery, Zhejiang Spine Surgery Centre, the Second Affiliated Hospital and Yuying Children's Hospital of Wenzhou Medical University, Second Medical School of Wenzhou Medical University, Wenzhou 325027, China; ${ }^{2}$ NeuroSpine Surgery Research Group (NSURG), Prince of Wales Private Hospital, University of New South Wales, Sydney, Australia; ${ }^{3}$ Department of Orthopaedic Surgery, Rush University Medical Center, Chicago, IL, USA; ${ }^{4}$ Orthopaedic and Traumatology Department, “G. D’Annunzio” University, Chieti, Italy; ${ }^{5}$ Department of Neurological Surgery, Thomas Jefferson University, Philadelphia, PA, USA

Contributions: (I) Conception and design: AM Wu, XY Wang; (II) Administrative support: Y Lin, WF Ni, XY Wang; (III) Provision of study materials or patients: AM Wu, D Chen, CH Chen, ZK Lin, L Tang, XY Wang; (IV) Collection and assembly of data: AM Wu, D Chen, CH Chen, YZ Li, L Tang, XY Wang; (V) Data analysis and interpretation: AM Wu, D Chen, CH Chen, Y Lin, WF Ni, XY Wang; (VI) Manuscript writing: All authors; (VII) Final approval of manuscript: All authors.

Correspondence to: Xiang-Yang Wang, MD, PhD. Department of Spine Surgery, Zhejiang Spine Surgery Centre, the Second Affiliated Hospital and Yuying Children's Hospital of Wenzhou Medical University, Second Medical School of Wenzhou Medical University, Wenzhou 325027, China. Email: knightman@yeah.net.

\begin{abstract}
The distal fixation in thoracolumbar deformity surgery can be challenging for spine surgeons. When isolated S1-pedicle screws are utilized as the sole distal fixation in long thoracolumbar posterior constructs, there is a high rate of failure, due to loosening, breakage, and pseudarthrosis. Unfortunately, with iliac screw fixation the entry point at the posterior superior iliac spine requires considerable soft tissue dissection and may potentially increase the likelihood of wound complications. S2-alar-iliac (S2AI) screw fixation technique was developed recently to provide increased fixation with a lower profile screw and rod construct. These screws can be inserted with percutaneous or free hand techniques. This fixation also has comparable biomechanical properties to the S1 iliac screw. This technique may provide advantages such as decreased rates of reoperation, surgical site infection, wound dehiscence and symptomatic screw prominence as compared to traditional iliac screw fixation. The purpose of this manuscript is to review the S2AI screw fixation literature including anatomy, technique, biomechanics, and clinical outcomes.
\end{abstract}

Keywords: S2-alar-iliac screw fixation; deformity; S2AI; pelvic fixation

Received: 17 July 2017; Accepted: 10 October 2017; Published: 15 December 2017.

doi: 10.21037/amj.2017.12.02

View this article at: http://dx.doi.org/10.21037/amj.2017.12.02

\section{Introduction}

Distal fixation of the end of thoracolumbar deformities can be challenging. Isolated S1-pedicle screw fixation is reported to have a high rate of pullout failure or breakage (up to $44 \%$ ), and pseudarthrosis (up to $33 \%$ ) (1-3). Some modified techniques have been introduced to improve the fixation strength and decrease the failure rate, including traditional iliac fixation, S1 cemented augmentation, S1 bicortical screws and S2 alar screw fixation (4-6). Traditional iliac screw fixation has improved resistance to pullout (7). The combination of the iliac screws and S1-pedicle screws for distal fixation can protect the S1 screw from failure and increase the rate of fusion $(8,9)$.

The traditional iliac screw entry point is at the posterior superior iliac spine and requires considerable soft tissue dissection in order to remove the bone block for screw insertion. Iliac screws sit in a lateral position compared to the $\mathrm{S} 1$ pedicle screw; thus, an offset connector is used to connect the iliac screw to the rod. However, this has the 


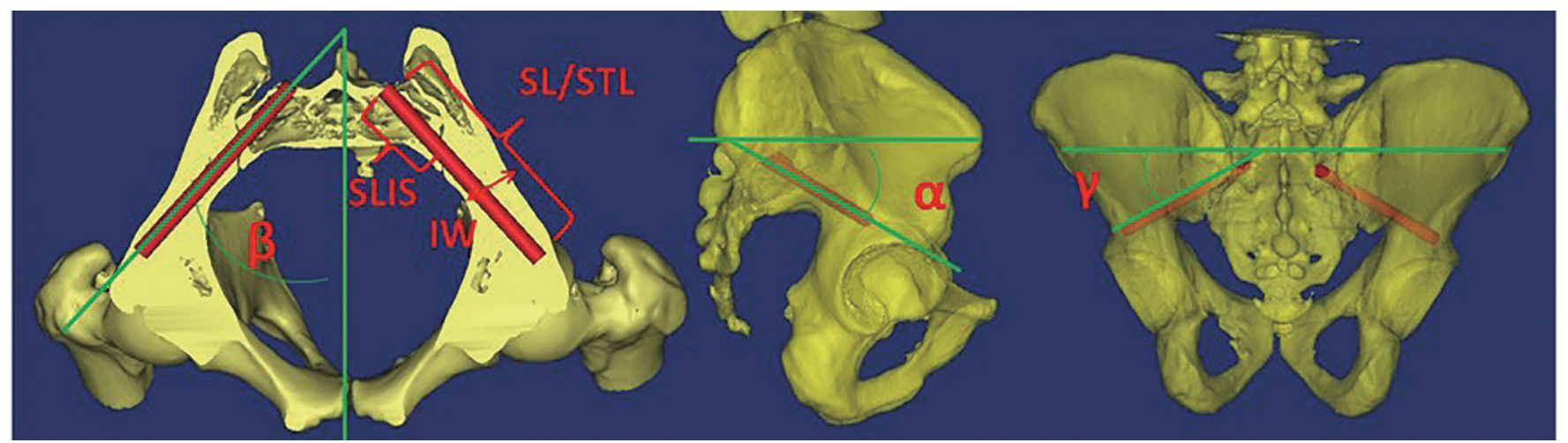

Figure 1 Representation of the parameters measured on CT images or cadaveric specimens. SL/STL, the screw length or screw trajectory length; SLIS, the screw length of the intrasacral part; IW, the iliac width defined as the narrowest iliac width measured between the inner cortices in the transverse plane; $\alpha$, the angle between screw trajectory and horizontal line in the sagittal plane; $\beta$, the lateral trajectory angulation in the transverse plane; $\gamma$, the angle between screw trajectory and middle vertical line in the coronal plane.

potential to increase the risk of wound complications, and increase post-operative pain in patient secondary to the extensive soft tissue manipulation. Moreover, the short distance between the screw end and skin may result in instrumentation prominence and subsequent pain $(9,10)$.

To overcome these challenges, a novel S2-alar-iliac (S2AI) screw fixation technique has been developed $(11,12)$. The S2AI screw entry point is medial to the iliac screw, requiring less soft tissue dissection, and avoiding instrumentation prominence. As such, this technique is a potential alternative fixation to Galveston or iliac screw fixation.

\section{Anatomy}

In order to illustrate the feasibility of the S2AI screw fixation and provide instructive data, several anatomic studies were conducted on computed tomography (CT) and cadaveric specimens (11,13-16). Parameters measured included (Figure 1): SL/STL: screw length or screw trajectory length; SLIS: screw length of the intrasacral part; IW: iliac width as defined by the narrowest iliac width measured between the inner cortices in the transverse plane; $\alpha$ : angle between screw trajectory and horizontal line in the sagittal plane; $\beta$ : lateral trajectory angulation in the transverse plane; and $\gamma$ : angle between screw trajectory and middle vertical line in the coronal plane. Typical S2AI screw trajectory parameters published previously $(11-14,17)$ are summarized in Table 1. The angle between screw trajectory and horizontal line in the sagittal plane ranges from $27.5^{\circ}$ to $48.8^{\circ}$, and averages $27.5^{\circ}$ to $39.0^{\circ}$. The lateral trajectory angulation in the transverse plane ranges from $30.8^{\circ}$ to $67.3^{\circ}$, and averages $32.4^{\circ}$ to $52.2^{\circ}$. The angle between screw trajectory and middle vertical line in the coronal plane ranges from $19^{\circ}$ to $49.2^{\circ}$, and averages $29.0^{\circ}$ to $34.6^{\circ}$.

\section{Technique procedure}

Reported mean values for iliac bone width range from $12.2-18.5 \mathrm{~mm}$ in different studies $(12,13,17)$. Therefore, screws with diameter of $6.5 \mathrm{~mm}$ are suitable for most patients and 7.5 and $8.5 \mathrm{~mm}$ screws should also be well tolerated. The length of screw could be chosen from 65 to $120 \mathrm{~mm}$ depending on the specific anatomy of individuals.

The optimal entry point of S2AI screw is located approximately $1 \mathrm{~mm}$ inferior and $1 \mathrm{~mm}$ lateral to the $\mathrm{S} 1$ dorsal foramen (11) (Figure 2), which is more medial and lower profile than iliac screw fixation. After determining the screw entry point, a drill or probe is used to fashion the screw trajectory (Figure 3), which can vary among individuals. Preoperative screw trajectory measurements and intra-operative imaging may help optimize screw trajectory.

In 2015, Park et al. (18) reported the free hand S2AI insertion technique on cadaveric specimen. The midpoint between the S1 and S2 foramen and $2 \mathrm{~mm}$ medial to the lateral sacral crest was chosen as the entry point. After insertion of eight S2AI screws, visual and C-arm evaluation of the screw trajectory demonstrated accurate placement of all screws, with no violation of the sciatic notch, acetabulum, or pelvic cavity. The authors suggested that the free hand technique could reduce radiation exposure and surgical time. 
Table 1 S2AI screw trajectory parameters reported in the literature

\begin{tabular}{|c|c|c|c|c|c|c|c|}
\hline Parameters & O'Brien 2009 & O'Brien 2010 & Chang 2009 & Zhu 2013 & Zhu 2013 & Yamada 2017 & Yamada 2017 \\
\hline $\begin{array}{l}\text { Method of } \\
\text { evaluation }\end{array}$ & $\begin{array}{l}\text { Fresh cadaveric spine } \\
\qquad(n=10)\end{array}$ & $\begin{array}{l}\text { Fresh cadaveric } \\
\text { spine }(n=8)\end{array}$ & CT $(n=20)$ & $\begin{array}{l}\text { CT (male) } \\
\quad(n=30)\end{array}$ & $\begin{array}{c}\text { CT (female) } \\
(n=30)\end{array}$ & $\begin{array}{l}\text { CT (male) } \\
(n=40)\end{array}$ & $\begin{array}{l}\text { CT (female) } \\
\quad(n=40)\end{array}$ \\
\hline \multicolumn{8}{|l|}{$\mathrm{SL} / \mathrm{STL}(\mathrm{mm})$} \\
\hline Left & $84.0 \pm 10.7[70-100]$ & $89.5 \pm 18.7(69-118.2)$ & $\begin{array}{l}106.3 \pm 8.9^{\#} \\
(88.3-124)\end{array}$ & $121.3 \pm 8.3^{\#}$ & $114.8 \pm 9.4^{\#}$ & $121.5 \pm 10.3$ & $113.8 \pm 9.6$ \\
\hline Right & $84.0 \pm 10.7[70-100]$ & $95.4 \pm 20.4(71.3-120)$ & $\begin{array}{c}103.7 \pm 9.9^{\#} \\
(77.5-122.5)\end{array}$ & $120.6 \pm 7.5^{\#}$ & $115.7 \pm 8.2^{\#}$ & $121.8 \pm 10.1$ & $112.7 \pm 9.1$ \\
\hline \multicolumn{8}{|l|}{ SLIS (mm) } \\
\hline Left & $42.0 \pm 11.0(25.6-59.4)$ & $28.2 \pm 9.7(10-35)$ & $\begin{array}{c}35.5 \pm 4.6 \\
(25.7-43.4)\end{array}$ & $26.2 \pm 3.3$ & $27.7 \pm 6.0$ & - & - \\
\hline \multicolumn{8}{|l|}{ IW (mm) } \\
\hline Left & - & - & $\begin{array}{c}12.4 \pm 1.9 \\
(10.4-17.3)\end{array}$ & $17.0 \pm 3.5$ & $14.8 \pm 2.5$ & $18.1 \pm 3.4$ & $15.9 \pm 2.8$ \\
\hline Right & - & - & $\begin{array}{c}12.2 \pm 2.1 \\
(7.5-16.9)\end{array}$ & $17.0 \pm 2.8$ & $14.9 \pm 2.6$ & $18.5 \pm 3.7$ & $16.0 \pm 3.1$ \\
\hline \multicolumn{8}{|l|}{$\alpha\left({ }^{\circ}\right)$} \\
\hline Left & - & - & $\begin{array}{c}38.4 \pm 5.5 \\
(28.5-48.8)\end{array}$ & $29.2 \pm 8.6$ & $34.5 \pm 6.6$ & $27.5 \pm 6.8$ & $33.4 \pm 6.4$ \\
\hline \multicolumn{8}{|l|}{$\gamma\left({ }^{\circ}\right)$} \\
\hline Left & $32.0 \pm 5.3(21.6-40.0)$ & $29.4 \pm 7.7(22.9-45.0)$ & - & - & - & - & - \\
\hline Right & $34.6 \pm 6.6(24.5-49.2)$ & $29.0 \pm 9.8(19.0-46.2)$ & - & - & - & - & - \\
\hline
\end{tabular}

\section{Biomechanics}

In 2013, O'Brien et al. (19) used seven human cadaveric spines to compare the biomechanical properties of $65-\mathrm{mm}$ S2AI screws, 80-mm S2AI screws, and 90-mm iliac screws. The authors found that $65-\mathrm{mm} \mathrm{S} 2 \mathrm{AI}$ screws were biomechanically equivalent to $80-\mathrm{mm}$ S2AI screws and 90-mm iliac screws. Upon modification of S2AI screw fixation to penetrate through the posterior iliac cortex (quad-cortical S2AI screw fixation), no significant differences in biomechanical properties were demonstrated 


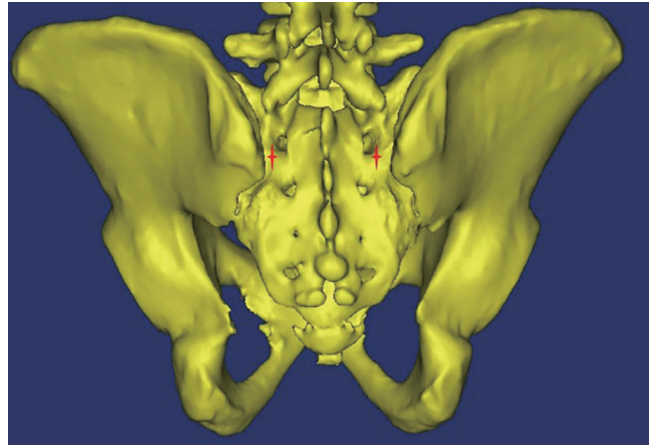

Figure 2 The optimal entry point (red cross) of S2AI screw is located approximately $1 \mathrm{~mm}$ inferior and $1 \mathrm{~mm}$ lateral to the $\mathrm{S} 1$ dorsal foramen.

as compared to the previous fixation models. The cadaveric biomechanical study of Burns et al. (20) also found that the S2AI and iliac screws had similar biomechanical properties in regards to construct stiffness and failure. Hoernschemeyer et al. (21) found that S2AI screw fixation has a consistent trend towards increased construct stiffness, but was not statistically significant.

Another cadaveric biomechanical study conducted by Sutterlin et al. (22) compared five different models: L2-S1 pedicle screws fixation; L2-S1 pedicle screws fixation + S2AI screw fixation; L2-S1 pedicle screws fixation + L5/S1 TLIF (transforaminal lumbar interbody fixation); L2-S1 pedicle screws fixation + L5/S1 AxiaLIF (axial lumbar interbody fixation); and L2-S1 pedicle screws fixation + S2AI screw fixation + L5/S1 AxiaLIF. Strain gauges were placed on two S1 screws and one rod at the level of L5/S1. They found that the S2AI screws can reduce the strain on S1 screws during flexion-extension, lateral bending and axial torsion and can reduce rod strain during lateral bending and axial torsion as compared to AxiaLIF and interbody instrumentation models. However, this came at the expense of increased rod flexion-extension strain.

\section{Preliminary clinical results}

Sponseller et al. (23) reported on 32 consecutive pediatric patients who underwent S2AI screw fixation and found that the correction of pelvic obliquity and Cobb angles were $20^{\circ} \pm 11^{\circ}(70 \%)$ and $42^{\circ} \pm 25^{\circ}(67 \%)$, respectively. Compared to the 27 control patients who underwent spinal fusion and pelvic fixation with sacral or iliac screws, S2AI screw fixation demonstrated significantly better pelvic obliquity correction. Additionally, there were no vascular or neurologic complications, deep surgical site or wound infections reported in the S2AI group, and only four patients that developed superficial wound infections. In contrast, the control group developed three deep wound infections, and two instances of superficial wound infection or partial wound dehiscence. CT images obtained for 18 patients in the S2AI group showed no screw penetration into the pelvis, one screw tip with lateral protrusion $(<5 \mathrm{~mm})$, and one asymptomatic breakage of a 7-mm S2AI screw neck that did not require revision. Of note, one S2AI patient reported postoperative sacroiliac joint pain, requiring revision with longer screws bilaterally.

Mazur et al. (24) reported on 13 patients treated by S2AI screws fixation (26 S2AI screws), and found partial peri-screw lucency in 7 S2AI screws $(27 \%)$ was found in 5 patients (38\%), without major screw-related complications or sacroiliac joint degeneration. Mazur et al. (25) also used S2AI fixation in treatment of pyogenic vertebral diskitis and osteomyelitis at the lumbosacral junction. They suggested that S2AI fixation could provide rigid posterior fixation.

Ilyas et al. (26) compared S2AI to traditional iliac screw fixation and found S2AI screw fixation had decreased the rate of implant loosening, acute wound infections, delayed wound problems and revision surgery. A retrospective comparative study conducted by Elder et al. (27) also found that S2AI had lower rates of reoperation, surgical site infection, wound dehiscence and symptomatic screw prominence than iliac screw fixation. This study showed similar rates of pseudarthrosis, proximal junctional kyphosis and functional outcomes between S2AI versus iliac screw fixation. However, these studies are done retrospectively with short term follow up. Future prospective, long-term follow-up studies need to be conducted, with inclusion of joint penetration, and sacroiliac joint fusion or degeneration in outcome assessments $(28,29)$.

\section{Minimally invasive S2AI screw fixation}

S2AI screws can also be inserted percutaneously. O'Brien et al. (14) performed percutaneous S2AI fixation on eight cadaveric spines, with visualization of the first dorsal foramen through standard anteroposterior and inlet radiographs, avoiding visceral or neurovascular structure injury. Martin et al. (30) also performed percutaneous S2AI screw fixation on two patients (a 69-year-old female with follicular thyroid carcinoma metastatic to the sacrum and a 55-year-old male with a sacral fracture), reporting minimal blood loss without intraoperative complications 

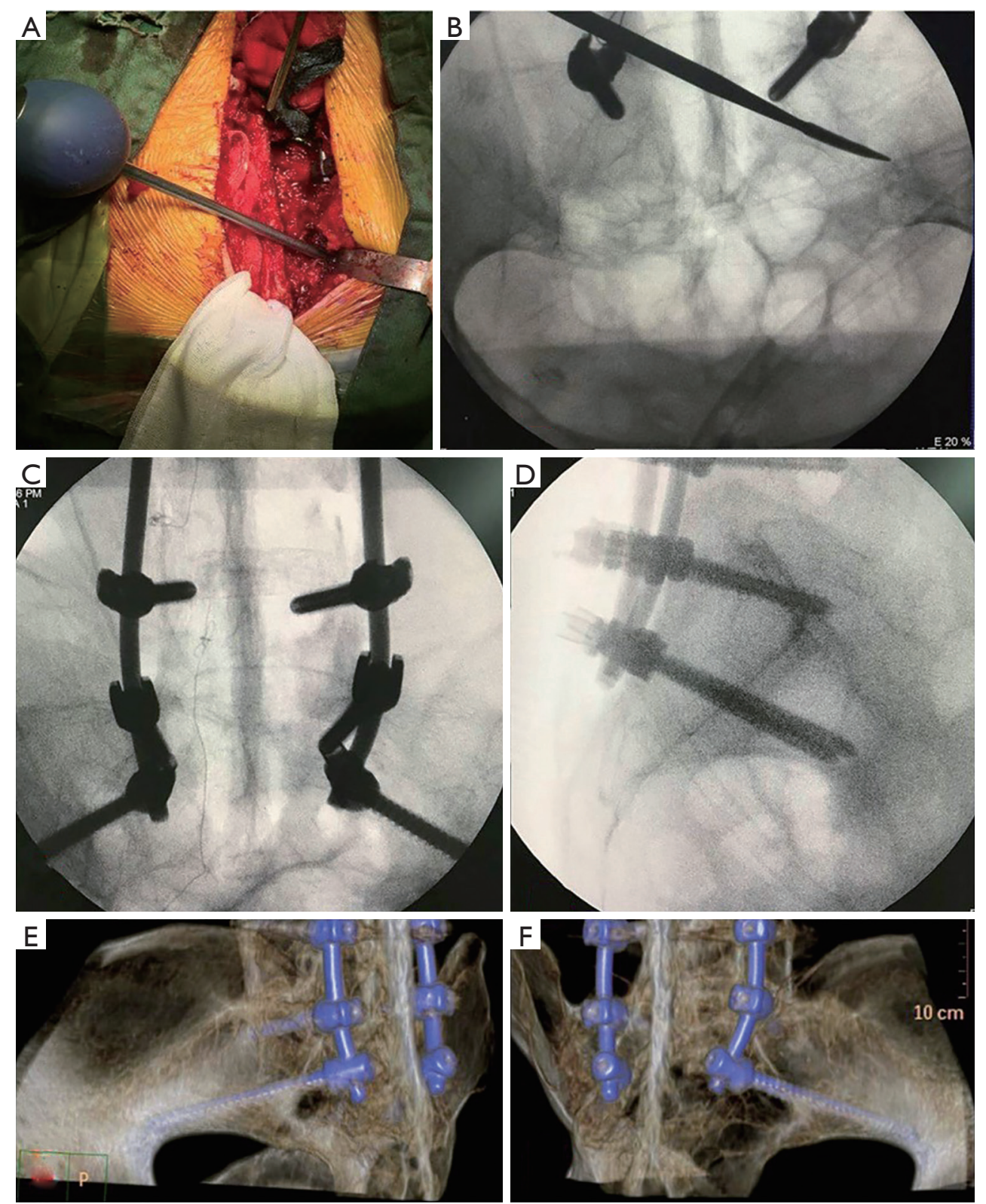

Figure 3 Intra-and post-operative images of the S2AI screw fixation technique. (A) Utilization of a probe to determine screw trajectory; (B) intra-operative fluoroscopy indicating accurate probe trajectory through the sacral iliac joint and into the iliac bone; Intra-operative anteroposterior (C) and lateral (D) fluoroscopy demonstrating S2AI screw fixation; (E,F) post-operative 3D CT reconstruction of S2AI screws fixation. S2AI, S2-alar-iliac.

and immediate achievement of stability. El Dafrawy and Kebaish (31) reported on a 65 -year-old woman who had an iliac stress fracture that progressed to nonunion. The authors performed the percutaneous S2AI screw fixation technique on her, with symptom relief reported at 2 months and radiographic union at 6 months. Funao et al. (32) additionally reported that the use of percutaneous of S2AI screw fixation was effective in the treatment of two cases of spondylodiscitis (one at L4-5, another at L5-S1). All these studies support that percutaneous S2AI screw fixation is a feasible and safe technique, with the added benefit of limited soft tissue damage. 


\section{Image-/robotic-guided S2AI screw fixation}

Hu et al. (33) retrospectively reviewed the use of robotic guidance to insert $35 \mathrm{~S} 2 \mathrm{AI}$ screws in 18 patients and reported no intra-operative complications with all screws demonstrating accurate trajectories on post-operative CT scans. To confirm the placement of the screws, the authors measured the distance between the pre-operative planned screws and post-operative inserted screws at two sites (one at the screw entry point, the other at the $30 \mathrm{~mm}$ depth point). They found that post-operative screws deviated

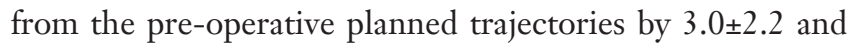
$2.1 \pm 1.3 \mathrm{~mm}$ in the axial plane at the screw entry point and $30 \mathrm{~mm}$ depth point, respectively, and $1.8 \pm 1.6$ and $1.2 \pm 1.1$ $\mathrm{mm}$ in the lateral plane at the screw entry point and $30 \mathrm{~mm}$ depth point, respectively.

Bederman et al. (34) utilized robotic guidance to insert 31 S2AI screws and determined that all screws' trajectories were placed accurately. Hyun et al. (35) also used robotic guidance to insert S2AI screws on four adult spinal deformity patients, and found that average surgical time was $13 \mathrm{~min}$ and $5.3 \mathrm{~s}$ of fluoroscopy per screw. All S2AI screws were placed accurately, without intra- or post-operative complications.

Image-/robotic-guided S2AI screw fixation can be performed by traditional open approach or minimally invasive approach. Current retrospective studies suggest that image-/robotic-guided S2AI screw fixation is a feasible and safe option for accurate screw placement.

\section{Conclusions and key points}

(I) The S2AI screw fixation is an anatomically feasible pelvic fixation technique, requiring less soft tissue dissection and avoiding instrumentation prominence;

(II) The S2AI screw entry point is approximately $1 \mathrm{~mm}$ inferior and $1 \mathrm{~mm}$ lateral to the $\mathrm{S} 1$ dorsal foramen;

(III) The diameter of S2AI screws ranges from 6.5 to $8.5 \mathrm{~mm}$, and the length ranges from 65 to $120 \mathrm{~mm}$;

(IV) The S2AI screw can be inserted percutaneously or free handedly;

(V) There is no significant difference in biomechanical properties between S2AI and iliac screws;

(VI) Retrospective, short-term outcomes reported in the literature show that S2AI has lower rates of reoperation, surgical site infection, wound dehiscence and symptomatic screw prominence than iliac screw fixation;
(VII) Image or robotic guidance may provide a feasible and safe option for accurate screw placement.

\section{Acknowledgements}

Funding: This work was funded by the National Natural Science Foundation of China [81501933, 81572214], Wenzhou Leading Talent Innovative Projects (RX2016004), Wenzhou Municipal Science and Technology Bureau (Y20170389), Zhejiang Provincial Medical Technology Foundation of China under (2018KY129), Zhejiang Provincial Natural Science Foundation of China (LY14H060008). The funders had no role in the design, execution, or writing of the study.

\section{Footnote}

Conflicts of Interest: The authors have no conflicts of interest to declare.

\section{References}

1 Mayer M, Stephan D, Resch H, et al. Biomechanical Comparison of Sacral Fixation Characteristics of Standard S1-Pedicle Screw Fixation versus a Novel Constrained S1-Dual-Screw Anchorage in the S1-Pedicle and S1-Alar Bone. Spine (Phila Pa 1976) 2015;40:1890-7.

2. Kebaish KM. Sacropelvic fixation: techniques and complications. Spine (Phila Pa 1976) 2010;35:2245-51.

3. Devlin VJ, Boachie-Adjei O, Bradford DS, et al. Treatment of adult spinal deformity with fusion to the sacrum using CD instrumentation. J Spinal Disord 1991;4:1-14.

4. Dubory A, Bachy M, Bouloussa H, et al. Screw augmentation for spinopelvic fixation in neuromuscular spine deformities: technical note. Eur Spine J 2015;24:2580-7.

5. Koller H, Zenner J, Hempfing A, et al. Reinforcement of lumbosacral instrumentation using S1-pedicle screws combined with S2-alar screws. Oper Orthop Traumatol 2013;25:294-314.

6. Pham MH, Jakoi AM, Hsieh PC. S-1 and S-2-alar-iliac screw fixation via intraoperative navigation. Neurosurg Focus 2016;41 Video Suppl 1:1.

7. Schwend RM, Sluyters R, Najdzionek J. The pylon concept of pelvic anchorage for spinal instrumentation in the human cadaver. Spine (Phila Pa 1976) 2003;28:542-7.

8. Tsuchiya K, Bridwell KH, Kuklo TR, et al. Minimum 
5-year analysis of L5-S1 fusion using sacropelvic fixation (bilateral S1 and iliac screws) for spinal deformity. Spine (Phila Pa 1976) 2006;31:303-8.

9. Kuklo TR, Bridwell KH, Lewis SJ, et al. Minimum 2-year analysis of sacropelvic fixation and L5-S1 fusion using S1 and iliac screws. Spine (Phila Pa 1976) 2001;26:1976-83.

10. Stevens DB, Beard C. Segmental spinal instrumentation for neuromuscular spinal deformity. Clin Orthop Relat Res 1989;(242):164-8.

11. O'Brien JR, Yu WD, Bhatnagar R, et al. An anatomic study of the S2 iliac technique for lumbopelvic screw placement. Spine (Phila Pa 1976) 2009;34:E439-42.

12. Chang TL, Sponseller PD, Kebaish KM, et al. Low profile pelvic fixation: anatomic parameters for sacral alar-iliac fixation versus traditional iliac fixation. Spine (Phila $\mathrm{Pa}$ 1976) 2009;34:436-40.

13. Zhu F, Bao HD, Yuan S, et al. Posterior second sacral alar iliac screw insertion: anatomic study in a Chinese population. Eur Spine J 2013;22:1683-9.

14. O'Brien JR, Matteini L, Yu WD, et al. Feasibility of minimally invasive sacropelvic fixation: percutaneous S2 alar iliac fixation. Spine (Phila Pa 1976) 2010;35:460-4.

15. Wu AM, Chi YL, Ni WF, et al. The feasibility and radiological features of sacral alar iliac fixation in an adult population: a 3D imaging study. PeerJ 2016;4:e1587.

16. Kwan MK, Jeffry A, Chan CY, et al. A radiological evaluation of the morphometry and safety of S1, S2 and S2-ilium screws in the Asian population using three dimensional computed tomography scan: an analysis of 180 pelvis. Surg Radiol Anat 2012;34:217-27.

17. Yamada K, Higashi T, Kaneko K, et al. Optimal trajectory and insertion accuracy of sacral alar iliac screws. Acta Orthop Traumatol Turc 2017;51:313-8.

18. Park JH, Hyun SJ, Kim KJ, et al. Free Hand Insertion Technique of S2 Sacral Alar-Iliac Screws for Spino-Pelvic Fixation: Technical Note, Acadaveric Study. J Korean Neurosurg Soc 2015;58:578-81.

19. O'Brien JR, Yu W, Kaufman BE, et al. Biomechanical evaluation of S2 alar-iliac screws: effect of length and quad-cortical purchase as compared with iliac fixation. Spine (Phila Pa 1976) 2013;38:E1250-5.

20. Burns CB, Dua K, Trasolini NA, et al. Biomechanical Comparison of Spinopelvic Fixation Constructs: Iliac Screw Versus S2-Alar-Iliac Screw. Spine Deform 2016;4:10-5.

21. Hoernschemeyer DG, Pashuck TD, Pfeiffer FM. Analysis of the s2 alar-iliac screw as compared with the traditional iliac screw: does it increase stability with sacroiliac fixation of the spine? Spine J 2017;17:875-9.

22. Sutterlin CE 3rd, Field A, Ferrara LA, et al. Range of motion, sacral screw and rod strain in long posterior spinal constructs: a biomechanical comparison between S2 alar iliac screws with traditional fixation strategies. J Spine Surg 2016;2:266-76.

23. Sponseller PD, Zimmerman RM, Ko PS, et al. Low profile pelvic fixation with the sacral alar iliac technique in the pediatric population improves results at twoyear minimum follow-up. Spine (Phila $\mathrm{Pa} 1976$ ) 2010;35:1887-92.

24. Mazur MD, Mahan MA, Shah LM, et al. Fate of S2-AlarIliac Screws After 12-Month Minimum Radiographic Follow-up: Preliminary Results. Neurosurgery 2017;80:67-72.

25. Mazur MD, Ravindra VM, Dailey AT, et al. Rigid Posterior Lumbopelvic Fixation without Formal Debridement for Pyogenic Vertebral Diskitis and Osteomyelitis Involving the Lumbosacral Junction: Technical Report. Front Surg 2015;2:47.

26. Ilyas H, Place H, Puryear A. A Comparison of Early Clinical and Radiographic Complications of Iliac Screw Fixation Versus S2 Alar Iliac (S2AI) Fixation in the Adult and Pediatric Populations. J Spinal Disord Tech 2015;28:E199-205.

27. Elder BD, Ishida W, Lo SL, et al. Use of S2-Alar-iliac Screws Associated With Less Complications Than Iliac Screws in Adult Lumbosacropelvic Fixation. Spine (Phila Pa 1976) 2017;42:E142-9.

28. Tseng C, Liu Z, Qiu Y, et al. Editorial on "Use of S2-alariliac screws associated with less complications than iliac screws in adult lumbosacropelvic fixation". AME Med J 2017;2:56.

29. Gupta S, Smith E, Falk D, et al. S2 alar-iliac screws versus iliac screws for pelvic fixation. AME Med J 2017;2:58.

30. Martin CT, Witham TF, Kebaish KM. Sacropelvic fixation: two case reports of a new percutaneous technique. Spine (Phila Pa 1976) 2011;36:E618-21.

31. El Dafrawy MH, Kebaish KM. Percutaneous S2 alar iliac fixation for pelvic insufficiency fracture. Orthopedics 2014;37:e1033-5.

32. Funao H, Kebaish KM, Isogai N, et al. Utilization of a Technique of Percutaneous S2 Alar-Iliac Fixation in Immunocompromised Patients with Spondylodiscitis. World Neurosurg 2017;97:757 e11-8.

33. Hu X, Lieberman IH. Robotic-guided sacro-pelvic fixation using S2 alar-iliac screws: feasibility and accuracy. Eur Spine J 2017;26:720-5. 
34. Bederman SS, Hahn P, Colin V, et al. Robotic Guidance for S2-Alar-Iliac Screws in Spinal Deformity Correction. Clin Spine Surg 2017;30:E49-53.

doi: 10.21037/amj.2017.12.02

Cite this article as: $\mathrm{Wu} \mathrm{AM}$, Chen D, Chen CH, Li YZ, Tang L, Phan K, Singh K, Haws BE, Vanni D, Mosley YI, Prasad SK, Harrop JS, Lin ZK, Lin Y, Ni WF, Wang XY; on behalf of AME Spine Surgery Collaborative Group. The technique of S2-alariliac screw fixation: a literature review. AME Med J 2017;2:179.
35. Hyun SJ, Kim KJ, Jahng TA. S2 alar iliac screw placement under robotic guidance for adult spinal deformity patients: technical note. Eur Spine J 2017;26:2198-203. 